\title{
ECOLOGICAL PECULIARITIES OF COPPER CHEMICAL FORMS CONTENT IN THE ERODED SOILS
}

\author{
Tamara Leah \\ “Nicolae Dimo” Institute of Pedology, Agrochemistry and Soil Protection \\ e-mail: tamaraleah09@gmail.com,phone: 373-22 284861,fax:373-22 284859
}

\begin{abstract}
The content of total and chemical forms of copper, the features of the distribution and transformation of compounds of copper in none eroded; weakly, moderately, strongly eroded; accumulative soil - deluvial of Gray soils and Calcareous chernozems from Republic of Moldova are presented. Erosion process led to increase the chemical forms associated with clay minerals, carbonates, oxides, and reducing the mobile and humus organic forms. The losses of copper in different chemical forms consist 33-35\% from humus horizon of agricultural eroded soils. The data are using as ecological and diagnostically indicators of trace elements losses from soils surface.
\end{abstract}

Keywords: agriculture, chemical forms, copper, soil, transformation

\section{Introduction}

Chemical pollution of agricultural soils is one of the most actual problems. Avoid it completely is impossible, because pollution is consequence of the functioning of industrial society, but to be able to assess, predict and combat the negative consequences is possible. Special group of pollutant in agriculture are trace elements, inclusive copper, which have the highest rates of toxicity for environment components. The characteristics of composition and structure of the soils have a significant role as a regulator of chemical compounds of trace elements that is realized by combining the processes of migration, transformation and accumulation in the agricultural degraded soils [1].

Study the composition of the compounds of the chemical elements in soils and their transformation mechanisms have more than half a century, but their importance is growing due to the need for adequate assessment of the current state of the contaminated soil, weather changing them, finding ways to improve them. For this purpose built combined fractionation scheme of compounds of elements in series and parallel processing of soil traditionally used agents and assuming calculated by finding the content of a number of compounds of elements, which are not specifically allocated in any of the schemes [2].

To assess the migration capacity of the copper $(\mathrm{Cu})$ and other trace elements in the food chain should take into account not only the total forms, but also their chemical forms associated with soil compounds, transformation in the degraded and polluted soils, as well as the ability of plants to withstand pollution. Despite intensive research, many questions of the absorption and transformation of metals in soils remain unresolved, and determine the relevance of researches. The aim of these investigations: to determinate the total forms of trace elements and verify the content of chemical forms, especially accessible for plants; to develop the ecological indicators to assessment the soil pollution in results of environment degradation.

\section{Material and method}

The research has been conducted on the Gray soils and Calcareous chernozems on the slope catena with different types of erosion: none eroded soil on the slope top - inter stream), strongly eroded on the slope bottom and deluvial soils in depression. The soils of catena are presented by the sequence of soils with approximate age, formed on the same parental material in similar climatic conditions, but having different characteristics in dependence of erosion degree. The purpose of researches is carrying out the features of the distribution and transformation of compounds of copper in the eroded Gray soils on the vineyards (contaminated by $\mathrm{Cu}$ ) and arable eroded Calcareous chernozems (background concentration of $\mathrm{Cu})$. The soil samples were collected from genetically humus horizon $(0-20 \mathrm{~cm})$ and calcareous horizon $(140-200 \mathrm{~cm})$. The total form of copper was determinate through classic methods of desegregations with hydrofluoric acid in combination with sulfuric acid. To research the copper fractions in eroded soils was used the parallel extraction scheme by different reagents. The total content and chemical forms of copper in soil samples were determinate by atomic absorption spectrophotometer method - AAS1.

\section{Result and discussion}

Systemic analysis of the chemical elements of soil reveals the relationship between their interrelations. The composition of any soil characterizes is an elementary system of chemical elements. The system of chemical elements includes in the phases of soils, influenced by interrelate processes of transformation and redistribution of matter and energy that occur in the real phase, soil profile and landscape-geochemical levels This system includes solidly associated mineral, organic and organic-mineral compounds, mobile forms of the liquid phases, the substance of the soil solution, soil air, and biota. 
The total Cu includes variety chemical forms in soil, inclusive: available and inaccessible to plants. The average content of $\mathrm{Cu}$ in gray soils is $27 \mathrm{mg} \mathrm{kg}^{-1}$, in calcareous chernozems $-35 \mathrm{mg} \mathrm{kg}^{-1}$. Accumulation of Cu in humus horizons of gray soils is the result of anthropogenic contemporary actions: $135 \mathrm{mg} \mathrm{kg}^{-1}$ in none eroded soil and $82 \mathrm{mg} \mathrm{kg}^{-1}$ in strongly eroded soil. The content of $\mathrm{Cu}$ in calcareous chernozems are below average: $23 \mathrm{mg} \mathrm{kg}^{-1}$ in none eroded, $15 \mathrm{mg}$ $\mathrm{kg}^{-1}$ in strongly eroded. The total content of $\mathrm{Cu}$ in carbonated horizons of soils are at the same level, without significant accumulation.

The accumulative deluvial soils are formed by accumulation of soil deposits rapidly increasing as a result of erosion on the slopes. Study on content and chemical forms of $\mathrm{Cu}$ in soils can be regarded as ecological and decisive factors of eroded and polluted soils. The total content of $\mathrm{Cu}$ in accumulative layers of soils under goes stratification depending on the texture and humus content. Gray soil cumulative layers I-II contains $37 \mathrm{mg} \mathrm{kg}^{-1} \mathrm{of} \mathrm{Cu}$, calcareous chernozem - $14 \mathrm{mg} \mathrm{kg}^{-1}$. In the calcareous chernozems the content of $\mathrm{Cu}$ is lower; the gray soil use for vineyard has a high content of total and chemical forms of $\mathrm{Cu}$. The content of total $\mathrm{Cu}$ in soils of catena is presented in Fig. 1 and 2 .

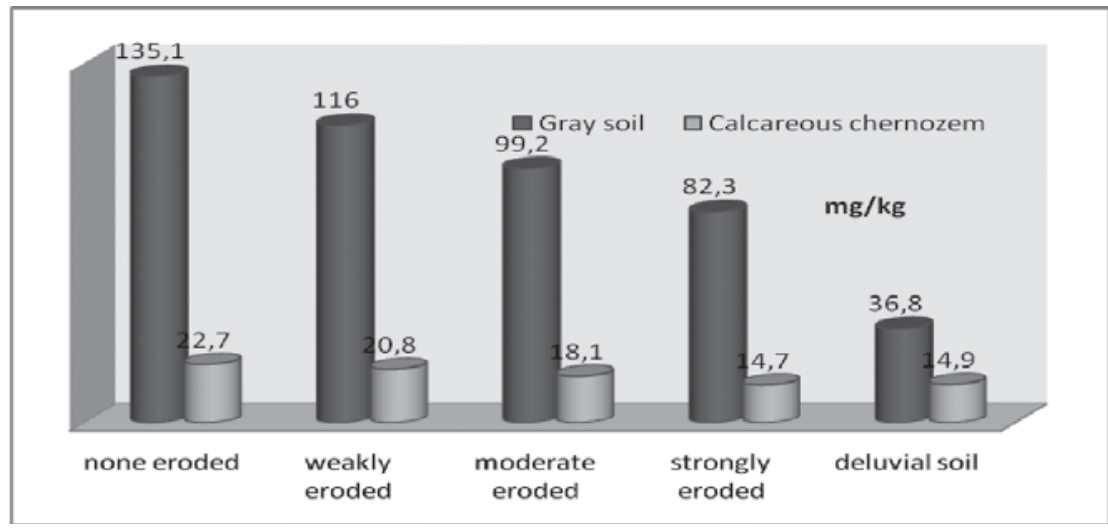

Fig. 1. The total content of $\mathrm{Cu}$ in humus horizon of soils

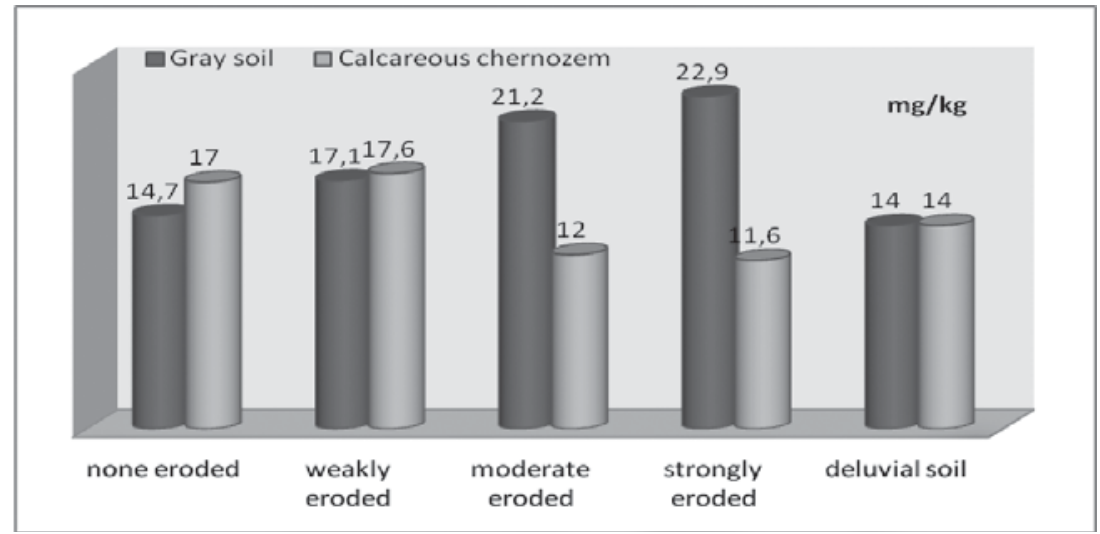

Fig. 2. The total content of $\mathrm{Cu}$ in calcareous horizon of soils

The chemical forms of $\mathbf{C u}$ in agricultural soils and vineyard are studied more intensively. Studies in this context are reduced to the following: soil components involved in the absorption of trace elements (including $\mathrm{Cu}$ ) are $\mathrm{Fe}-\mathrm{Mn}$ oxides, organic matter, carbonates and clay minerals. These components are considered the most important groups, participating and competing among themselves in the processes of absorption, transformation and accumulation of trace elements. To trying to know the transformation of these processes it brings a contribution to pedogeochemical researches of eroded and polluted soils, included in agricultural cycle [4].

The mobile and accessible chemical forms of $\mathbf{C u}$ available for plants in the gray soils consist 16-20\%, in calcareous chernozems - 8-9\% from total $\mathrm{Cu}$. These forms are proportional and well-define correlation with global content. The ions of $\mathrm{Cu}$ can be easily sediment by sulfides, carbonates and hydroxides. As a result the $\mathrm{Cu}$ becomes an element with low mobility in carbonated soils and horizons [4]. The content of mobile $\mathrm{Cu}$ in superficial humus layer is $1.0-1.7 \mathrm{mg} \mathrm{kg}^{-1}$. The mobility of $\mathrm{Cu}$ in eroded soils decreased in dependence by the duration of establishment of dynamic equilibrium in the soil after anthropogenic impact (fig. 3 and 4). 


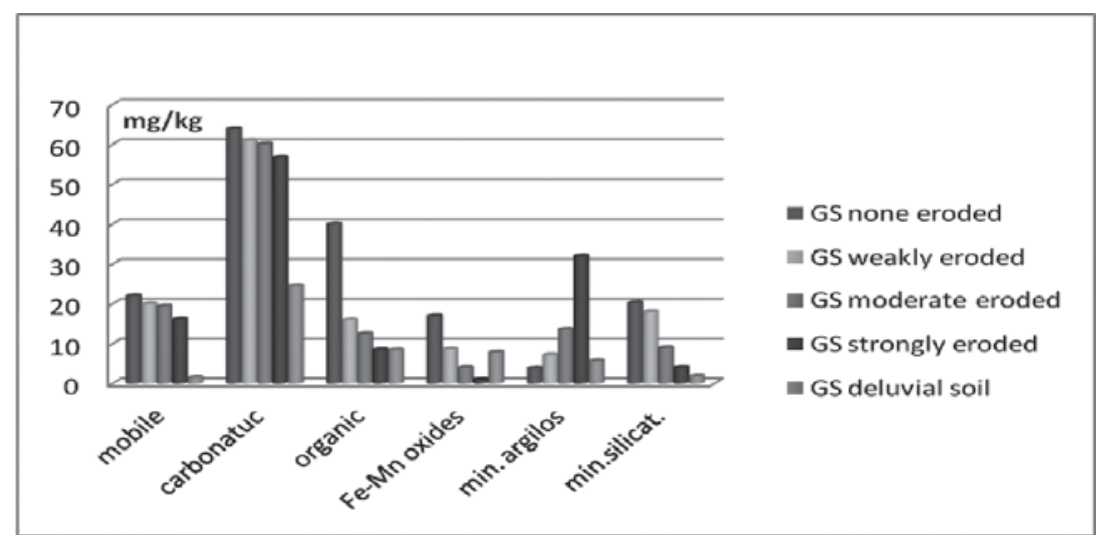

Fig. 3. Chemical forms of $\mathrm{Cu}$ content in the humus horizon of Gray Soils (GS)

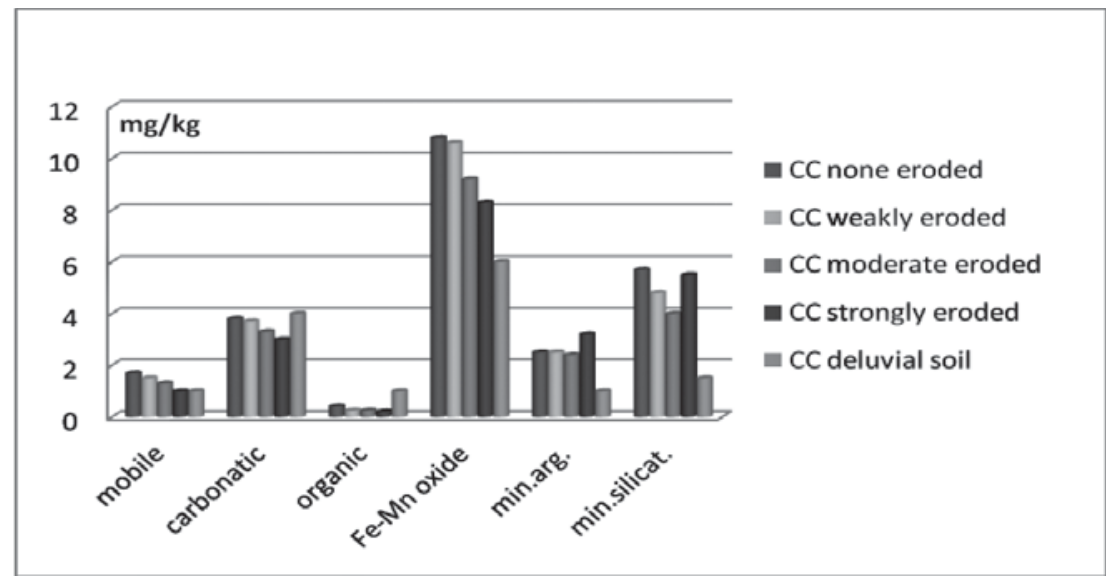

Fig. 4. Chemical forms of $\mathrm{Cu}$ content in the calcareous horizon of Calcareous Chernozem (CC)

Chemical forms inaccessible to plants find in poorly soluble or practically insoluble salts, organic and organicmineral compounds, primary and secondary minerals. They consist up to $70-80 \%$ in the investigated soils. Copper may come inaccessible for plants through physical-chemical and biochemical mobility processes, from inaccessible to easy accessibility and ionic forms (in associate with carbonates, organic matter, Fe-Mn oxides). These forms constitute the potential mobility reserves of $\mathrm{Cu}$ for plants. But, practically insoluble salts and crystal lattices of minerals are locked the nutrients in inaccessible positions; these are the immobilization reserves (primary minerals).

Carbonates are a common component of soils where evaporation prevails on atmospheric precipitation. Thus, $\mathrm{Ca}^{++}$is presented in soil solution. The most widespread and mobile form of calcium carbonate in soils is calcite, which has a large dispersed and actions very much on soil $\mathrm{pH}$, therefore, on the behavior of soil microelements. Therefore, the $\mathrm{Cu}$ can be settled with the carbonates [2].

Carbonates in the soil contribute to the fixation of $\mathrm{Cu}$ in result of reducing the content of exchange forms, chemisorptions on the surface of the carbonates and increasing ability of the sorption Fe-Mn oxides. The chemical forms associated with carbonates consist in carbonate chernozems up $17-29 \%$ of the $\mathrm{Cu}$ total content, in the gray soils $47-69 \%$. There is a proportional increase of $\mathrm{Cu}$ in calcareous forms with the degree of erosion and carbonates content. In accumulative layer of deluvial typical soils this forms consist $30 \%$ and $67 \%$, respectively, with a considerable decrease in the under layer horizons.

The organic matter contains the necessary plant nutrients in various connections and forms. Most organic compounds are capacity to associate the $\mathrm{Cu}$ in the complexes, which are soluble and insoluble in soil solution, in dependence of the nature and quantity of organic matter. Formation of organic complexes has a significant practical importance to control the biological accessibility and migration of $\mathrm{Cu}$ in the soils. Copper content associated with organic compounds consist from 0.4 to $0.2 \mathrm{mg} / \mathrm{kg}$ in the $0-20 \mathrm{~cm}$ horizon of carbonated chernozems, or $2 \%$ of the total $\mathrm{Cu}$. The humus horizon of gray none eroded soil contain about $40 \%$ of organically forms. In the deluvial soils were determined $7 \%$ of these forms. In humus horizons can accumulate and other organic-mineral compounds with increasing concentrations of carbonates. 
Fe-Mn oxides are specific soil components and have important meaning in retaining the trace elements. Absorbed turn around $\mathrm{Fe}$ hydroxide the $\mathrm{Cu}$ ions may eventually pass in to the occluded status. A considerable quantity of copper is adsorbed by Fe-Mn oxides in higher eroded and degraded soils. Distribution of these forms in the soil profiles is similar to distribution of total Fe. The calcareous eroded chernozems of the slope contain $48-54 \%$ of compounds with Fe-Mn oxides, the gray soils $-13-20 \%$ in dependence of erosion degree.

Minerals, especially clay (argillic) are a powerful accumulator of trace elements in soils. Some part of elements are fixed of the exchange form, other is recorded in the irreversibly form. Clay minerals can retain trace elements by ion exchange, chemisorptions, adsorption and occlusion [2].

A part of copper in soil is associated by clay and silicates minerals. The minerals have capacity to adsorption the copper ions from solution, especially in soils with high clay mineral content. Soil clay minerals have a high disperse degree and specific physic-chemical characteristics. The clay minerals are the active fraction of mineral soil matter as an ecological character and factor. Together with humus, these minerals formed a clay-humid soil complex. Therefore, a considerable quantity of $\mathrm{Cu}$ is associated with clay and silicates minerals. With increasing of soil erosion degree the content of $\mathrm{Cu}$ clay minerals forms increases and accumulated in the deluvial soils.

Large part of the primary minerals may associate the copper in immobile forms, which are the most resistant chemical forms of soils. The content of forms from primary minerals are higher than secondary minerals; from $25 \%$ in $0-20 \mathrm{~cm}$ layer of none eroded carbonate chernozem to $37 \%$ in heavily eroded chernozem; in the gray soil, respectively $-15 \%$ and $25 \%$ from total $\mathrm{Cu}$.

The eroded calcareous chernozems have a content of copper under optimal limits for plants. In carbonated chernozems dominate the chemical forms of $\mathrm{Cu}$ associated with primary minerals, carbonates, oxides, which are inaccessible to plants. The eroded soils of slopes need in organic fertilization which will conducting at increase the humus and capture available nutrients for plants. In the case when the soil is polluted (gray soil of vineyards), the distribution character of element on the soil compounds varies, and can serve as a diagnostic criteria in determination the type of contamination (anthropogenic or natural) and elaboration of prognoses of $\mathrm{Cu}$ behavior in the environment components.

\section{Conclusions}

Regularities of the distribution of copper chemical forms content in soils are influenced by erosion processes, agriculture use and soil composition.

1. Degree of $\mathrm{Cu}$ fixation by soil components showed that in the eroded soils the main role in their absorption is organic matter, Fe-Mn oxides, clay minerals. Among of these categories of chemical forms in which $\mathrm{Cu}$ are find in the soils, no precise separations, but gradual transition. Therefore, the great importance to separate chemical forms will determinate by the methods for establishing a balance between these forms for each type of soil.

2. The soil erosion increases the content of soluble forms and associated with clay minerals; decrease the forms of organic matter, oxides, and primary minerals. In none eroded, accumulative soils (deluvial) reduction occurs content of mobile forms, chemical forms of clay minerals compounds is lower. The content of chemical forms associated with carbonates and oxides is higher, increase in according to erosion degree on the slopes.

3. The research ecological characteristics of transformation of compounds of $\mathrm{Cu}$ in the soils can be used to assess the environmental impact of anthropogenic emissions. Established the mechanisms of interaction of $\mathrm{Cu}$ (other elements) in soils components serve to develop effective methods to remediate the contaminated soils. The revealed regularities in translocation of trace elements in plants can be used for the purposes of rationing of toxicants in soils.

4. Appropriate supervision of microelements in the eroded soils is not possible without knowing the factors which determining their mobility in soils. Knowing the chemical forms of microelements in the soils and natural anthropogenic processes that contribute to the formation and conversion of pollutant in soils, can allowing and finding ways to decontaminate the soils trough transformation one form to another form, immobilization of hazardous forms for plants and environment ambient.

\section{Acknowlegments}

This work was supported by the Joint Operational Programme "Black Sea Basin 2007-2013".

\section{References}

[1]. Leah, Tamara (2011). Modification of content and chemical forms of copper in agricultural grey forest soils. Î.E.P. Ştiința, Comb. Polig. Chisinau, 237-240 p. (rom.).

[2]. Motuzova, G.V. (1991). Composition of trace elements in soil: organization system, ecological importance, monitoring. M., p. 168-170, (rus).

[3]. Minchina, T.M., Motuzova, G.V., Nazarenco, O.G. (2009). The composition of heavy metals in soils. Everest. Rostov na Donu. 208 p. (rus).

[4]. Leah, Tamara (2010). Pollution of eroded soils by excess and deficiency of copper. Scientific paper „Horticulture”, LIII (53) 2010, „Ion Ionescu de la Brad”, Iaşi, p. 569-572. 